\title{
VOLUME 25 - ISSUE 1
}

February 2020

ISSN: 1092-8529

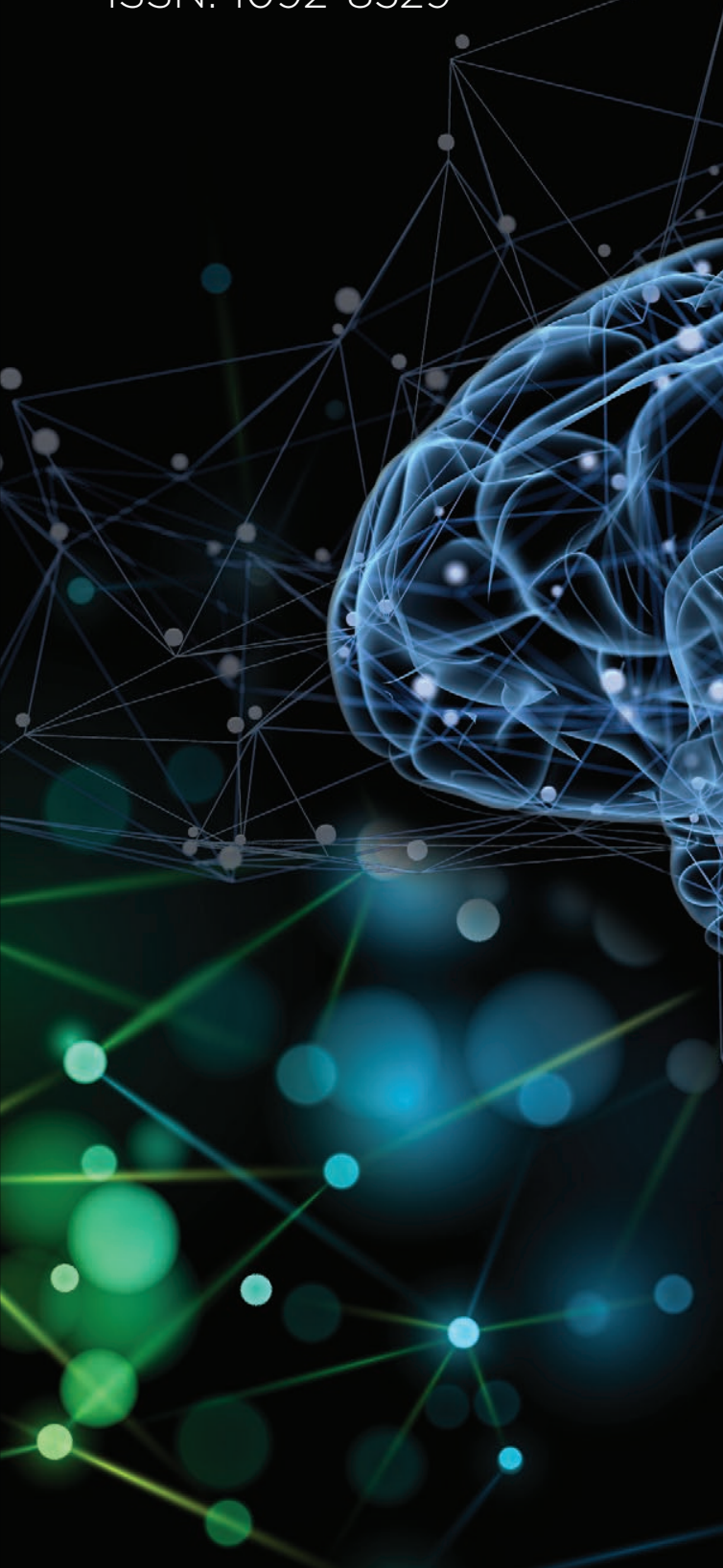




\section{CAMBRIDGE}

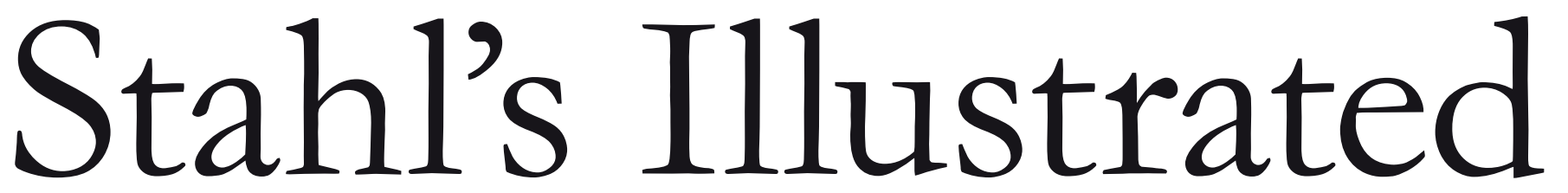

\section{Complete your collection at cambridge.org/stahlsillustrated}
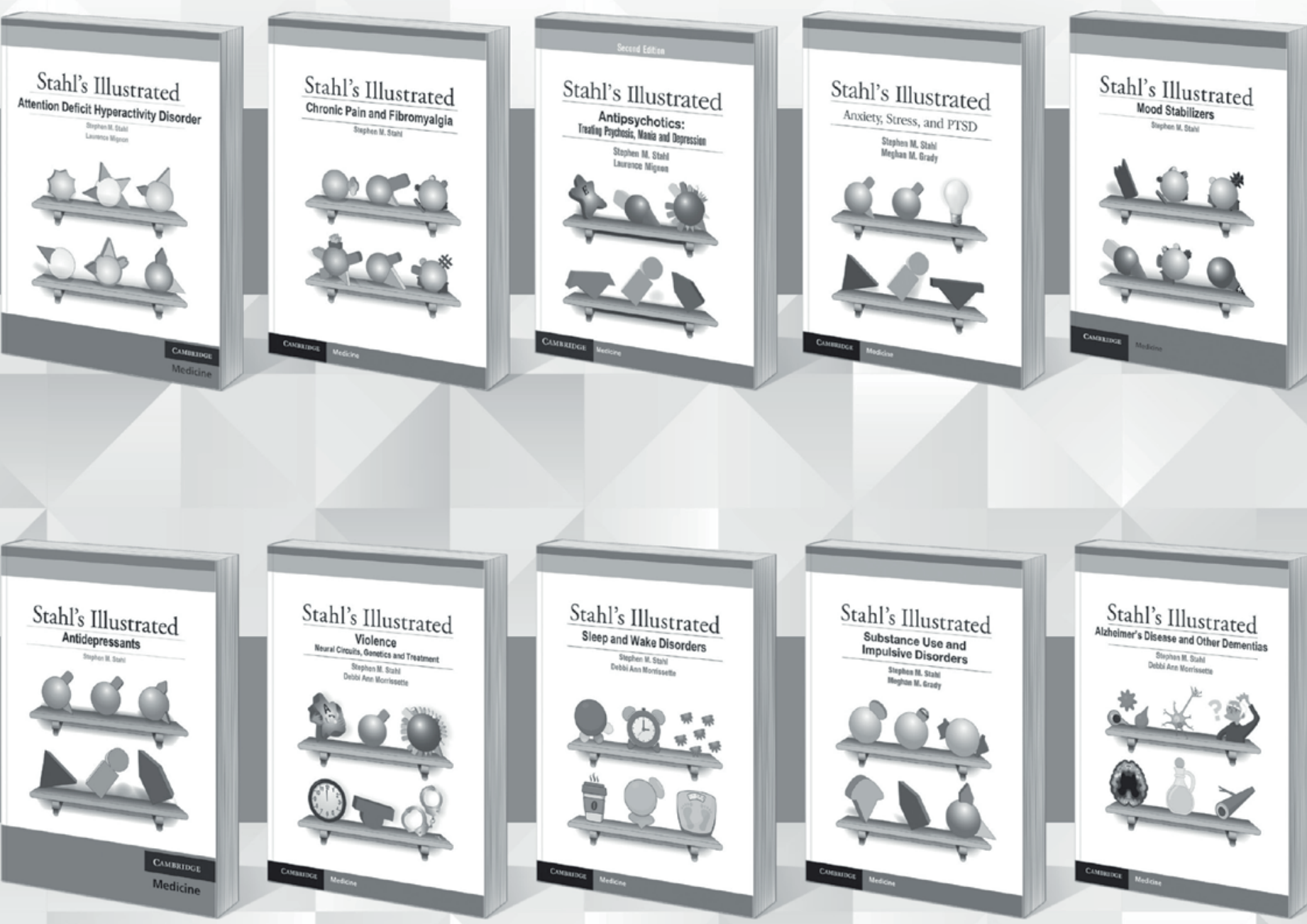


\section{VOLUME 25 ISSUE 1 FEBRUARY 2020}

\section{CNS SPECTRUMS}

\section{CONTENTS}

\section{REVIEWERS}

CNS Spectrums 2019 Peer Reviewers

\section{ORIGINAL RESEARCH}

The effect of caloric restriction on working memory in healthy non-obese adults

Emilie Leclerc, Alisson Paulino Trevizol, Ruth B. Grigolon, Mehala Subramaniapillai, Roger S. Mclntyre, Elisa Brietzke and Rodrigo B. Mansur

Links between sexuality, impulsivity, compulsivity, and addiction in a large sample of university students Austin W. Blum, Katherine Lust, Gary Christenson and Jon E. Grant

Demoralization in essential tremor: prevalence, clinical correlates, and dissociation from tremor severity Tess E. K. Cersonsky, Sarah Kellner, Sarah Morgan, Stephanie Cosentino, Brian B. Koo, John M. de Figueiredo and Elan D. Louis

Left rostrolateral prefrontal cortex lesions reduce suicidal ideation in penetrating traumatic brain injury Matteo Pardini, Jordan Grafman, Vanessa Raymont, Mario Amore, Gianluca Serafini, Michael Koenigs and Frank Krueger

Can sleep disturbance be a cue of mood spectrum comorbidity? A preliminary study in panic disorder Mario Miniati, Laura Palagini, Alessandra Maglio,

Donatella Marazziti and Liliana Dell'Osso
Noninvasive brain stimulation in rehabilitation of

1 hemispatial neglect after stroke Jitka Veldema, Kathrin Bösl, Günter Neumann, Geert Verheyden and Dennis Alexander Nowak

Clinical implications of directly switching antidepressants in well-treated depressed patients with treatment-emergent sexual dysfunction: a comparison between vortioxetine and escitalopram

Paula L. Jacobsen, George G. Nomikos, Wei Zhong, Andrew J. Cutler, John Affinito and Anita Clayton

Is problematic exercise really problematic?

A dimensional approach

Samuel R. Chamberlain and Jon E. Grant

An innovative approach for the assessment of mood disturbances in patients with eating disorders Lucia Tecuta, Giovanni Andrea Fava and Elena Tomba

\section{REVIEW ARTICLES}

Emotional distress, brain functioning, and biobehavioral processes in cancer patients: a neuroimaging review and future directions

Joaquim C. Reis, Michael H. Antoni and Luzia Travado

Early seizures after ischemic stroke: focus on thrombolysis

Gergely Feher, Zsuzsanna Gurdan, Katalin Gombos, Katalin Koltai, Gabriella Pusch, Antal Tibold

32 and Laszlo Szapary 
Stephen M. Stahl, Adjunct Professor of Psychiatry at the University of California San Diego, USA; Honorary Visiting Senior Fellow at the University of Cambridge, UK.

\section{Field Editors}

Bernardo Dell'Osso, University of Milan, Italy

Kostas N. Fountoulakis, Aristotle University of Thessaloniki, Greece

Joseph F. Goldberg, Icahn School of Medicine at Mount Sinai, USA

Donatella Marazziti, University of Pisa, Italy

Humberto Nicolini, National Institutes of Health, Minister of Health, Mexico

Stefano Pallanti, University of Florence, Italy

Thomas E. Schlaepfer, University Hospital Bonn, Germany

Frank I. Tarazi, Harvard Medical School, USA

Carlos A. Zarate, National Institute of Mental Health, USA

\section{Deputy Editor}

Thomas L. Schwartz, SUNY Upstate Medical University at Syracuse, USA

\section{Editorial Board}

Leslie Citrome, New York Medical College, USA

Christoph U. Correll, Hofstra Northwell School of Medicine, USA

Maria Conceição do Rosario, University of São Paulo Medical School, Brazil

Jeffrey L. Cummings, Cleveland Clinic, USA

Thilo Deckersbach, Harvard Medical School, USA

Bernardo Dell'Osso, University of Milan, Italy

Koen Demyttenaere, University Psychiatric Center KuLeuven, Belgium

Karen D. Ersche, University of Cambridge, UK

Nesrin Dilbaz, Üsküdar University NP Brain Hospital, İstanbul

Gianni Faedda, The Mood Disorders Center of New York, USA

Robert L. Findling, The Johns Hopkins Hospital, USA

Patrick R. Finley, University of California, San Francisco, USA

Kostas N. Fountoulakis, Aristotle University of Thessaloniki, Greece

Mark S. George, Medical University of South Carolina, USA

Ira D. Glick, Stanford University, USA

Joseph F. Goldberg, Icahn School of Medicine at Mount Sinai, USA

Jon Grant, University of Chicago, USA

Gregor Hasler, University of Berne, Switzerland

Eric Hollander, Albert Einstein College of Medicine and Montefiore Medical Center, USA

Daphne Holt, Harvard Medical School, USA

Oliver Howes, King's College, London, UK

Peter B. Jones, University of Cambridge, UK

Andres M. Kanner, University of Miami, USA

Antony D. Loebel, New York University School of Medicine, USA

Donatella Marazziti, University of Pisa, Italy

Roger Mclntyre, University of Toronto, Canada

Herbert Y. Meltzer, Northwestern University, USA

Philip Mitchell, University of New South Wales, Australia

Mary Moller, Pacific Lutheran University and Northwest Integrated Health, USA

Mark Muse, Muse Psychological Associates, USA

Humberto Nicolini, National Institutes of Health, Minister of Health, México

Andrew A. Nierenberg, Harvard Medical School, USA

Stefano Pallanti, University of Florence, Italy

Katharine A. Phillips, Weill Cornell Medical College, USA

Diego A. Pizzagalli, Harvard Medical School, USA

Mark H. Pollack, Rush University Medical Center, USA

Mark H. Rapaport, Emory University, USA

Irismar Reis de Oliveira, Universidade Federal da Bahia, Brazi

Trevor W. Robbins, University of Cambridge, UK

Peter P. Roy-Byrne, University of Washington School of Medicine, USA

Barbara J. Sahakian, University of Cambridge, UK

Gerard Sanacora, Yale University School of Medicine, USA

Alan F. Schatzberg, Stanford University School of Medicine, USA

Thomas E. Schlaepfer, University of Bonn, Germany

Thomas L. Schwartz, SUNY Upstate Medical University in Syracuse, USA

Erich Seifritz, University of Zürich, Switzerland

Jordan W. Smoller, Harvard Medical School, USA

Dan J. Stein, University of Cape Town (UCT), South Africa

Stephen Strakowski, University of Texas at Austin, USA

T. Scott Stroup, Columbia University, USA

Frank I. Tarazi, Harvard Medical School, USA

Michael E. Thase, University of Pennsylvania, USA

Michael Trimble, National Hospital for Neurology, Queen Square, London

Madhukar H. Trivedi, University of Texas Southwestern Medical Center, USA

Hiroyuki Uchida, Keio University School of Medicine, Japan

Susan Velasquez, California Department of State Hospitals, USA

Benedetto Vitiello, University of Turin, Italy

Karen Dineen Wagner, The University of Texas Medical Branch, USA

Katherine D. Warburton, California Department of State Hospitals, USA

Stephen R. Wisniewski, University of Pittsburgh, USA

Carlos A. Zarate, Jr., National Institute of Mental Health, USA

Joseph Zohar, Tel Aviv University, Israel

Managing Editor

Lisa Arrington, Cambridge University Press (larrington@cambridge.org) 


\section{Aims and Scope}

CNS Spectrums covers all aspects of the clinical neurosciences, neurotherapeutics and neuropsychopharmacology, particularly those pertinent to the clinician and clinical investigator. The journal features focused, in-depth reviews, perspectives and original research articles. New therapeutics of all types in psychiatry, mental health, and neurology are emphasized, especially first in man studies, proof of concept studies and translational basic neuroscience studies. Subject coverage spans the full spectrum of neuropsychiatry, focusing on those crossing traditional boundaries between neurology and psychiatry.

\section{Submitting Manuscripts to CNS Spectrums}

All submissions to CNS Spectrums should be prepared in accordance with the instructions for authors and in the style of the Journal. Manuscripts should be submitted through the dedicated CNS Spectrums ScholarOne Manuscripts website: http://mc.manuscriptcentral.com/cnsspectr

CNS Spectrums will consider and encourage the following types of articles for publication: Reviews-The review article is a comprehensive article summarizing and synthesizing the literature on various topics presented in a scholarly and clinically relevant fashion; Perspectives - The perspective article is a type of review that is a short, focused summary of a single recent advance, a sort of spotlight on the topic, which could be for example, a single point hypothesis or a novel model. It can stimulate debate and new research. Meta-guidelines-A meta-guideline is a "guideline of guidelines" put together by several leading figures in a field in which there are multiple competing guidelines that require synthesis and updating; Original Research-Reports the results of a clinical study and contains original research; the journal will also include Brainstorms and Editorials that shall be commissioned or written by the Editor-in-Chief

\section{Instructions for Contributors}

The Instructions for Contributors are available on the Cambridge Journals Online web site at: http://journals.cambridge.org/CNSifc

\section{Indexing}

CNS Spectrums is indexed by Index Medicus/MEDLINE and Web of Science (Thomson Reuters) as well as appearing in the annual Journal Citation Report. Introduced in 1996, the journal was acquired in whole by Cambridge University Press in November of 2011.

\section{Subscriptions}

Institutional print and electronic: £574/\$910; Institutional electronic only: £436/\$697.

\section{(c) Cambridge University Press 2020. All rights reserved.}

No part of this publication may be reproduced, in any form or by any means, electronic, photocopying, or otherwise, without permission in writing from Cambridge University Press. Policies, request forms, and contacts are available at: http://www.cambridge.org/rights/ permissions/permission.htm. Permission to copy (for users in the U.S.A.) is available from Copyright Clearance Center http://www. copyright.com, email: info@copyright.com.

Rights \& permissions requests can be applied for online within each article by clicking "Request Permissions" within the table of contents or in the fulltext version of a specific article. Requests will be processed via the CCC Rightslink system and processed immediately.

CNS Spectrums (ISSN: Print 1092-8529; eISSN: 2165-6509) is published bimonthly by Cambridge University Press.

\section{Postmaster}

Send address changes in the U.S.A., Canada, and Mexico to CNS Spectrums, Cambridge University Press, Journals Dept., One Liberty Plaza, 20th Floor, New York, NY 10006, U.S.A. Send address changes elsewhere to CNS Spectrums, Cambridge University Press, University Printing House, Shaftesbury Road, Cambridge CB2 8BS, England.

\section{Online availability}

CNS Spectrums is hosted on the Cambridge Core service at cambridge.org/cns

Institutional subscribers: Access to full-text articles online is only granted to subscription options offering an online component. Subscriptions must be activated by the purchasing institution using the instructions provided at the time of purchase; see information for subscribers at: http://journals.cambridge.org/

\section{Reprint and Advertising Sales}

Inquiries for bulk reprint sales should be sent to USReprints@cambridge.org. Advertising inquiries should be sent to M. J. Mrvica Associates, Inc., 2 West Taunton Avenue, Berlin, NJ 08009; Phone: 856-768-9360; Fax: 856-753-0064; Email: mjmrvica@mrvica.com. 